\title{
Diagnóstico Biológico e Molecular e Análise da Seqüência de Nucleotídeos do Gene da Proteína Capsidial de um Isolado do Apple stem pitting virus
}

\author{
Paula Radaelli $^{1 *}$, Osmar Nickel ${ }^{2}$, Jurema Schons ${ }^{1}$, Francisco J.L. Aragão ${ }^{3} \&$ Thor V. M. Fajardo ${ }^{2}$ \\ ${ }^{1}$ Faculdade de Agronomia e Medicina Veterinária, Universidade de Passo Fundo, CEP 99001-970, Passo Fundo, RS;

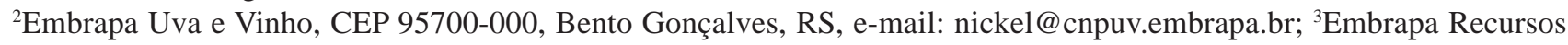 \\ Genéticos e Biotecnologia, CEP 70770-900, Brasília, DF
}

(Aceito para publicação em 06/09/2005)

Autor para correspondência: Osmar Nickel

RADAELLI, P., NICKEL, O., SCHONS, J., ARAGÃO, F.J.L. \& FAJARDO, T.V.M. Diagnóstico biológico e molecular e análise da seqüência de nucleotídeos do gene da proteína capsidial de um isolado do Apple stem pitting virus. Fitopatologia Brasileira 31:051-056. 2006.

\section{RESUMO}

O Apple stem pitting virus (ASPV) foi detectado por RT-PCR em amostras de cultivares de pereiras européias (Pyrus communis L.) cvs. Starkrimson e Abate Fetel, e asiáticas (P. pyrifolia var. culta) cvs. Kousui e Housui coletadas no início do outono de 2003 em pomar da Estação Experimental da Embrapa Uva e Vinho, Vacaria, RS. Utilizando várias combinações de oligonucleotídeos, foram amplificados fragmentos de DNA de 269 e 1554 pb, este último contendo o gene completo (1131 nt) da proteína capsidial do ASPV. Outro fragmento amplificado de 291 pb compreende parte do gene da polimerase viral. Estes fragmentos constituem-se em um excelente instrumento de diagnóstico do ASPV em pereiras. A comparação das seqüências de nucleotídeos do gene da proteína capsidial do ASPV com seqüências do banco de dados GenBank, revelou identidades de $89 \%$ com seqüências de um isolado alemão de macieira e de 85 a $88 \%$ com isolados poloneses, de pereiras. A indicadora herbácea Nicotiana occidentalis cv. 37B, inoculada mecanicamente com extrato foliar da cv. Housui, apresentou lesões locais necróticas, necrose foliar marginal e das nervuras. O ASPV também foi detectado por dot-ELISA nas cvs. Abate Fetel e Kousui, na cv. Starkrimson por imunoblot, e em Pyronia veitchii (Trabut) Guill. por enxertia de borbulhas da cv. Abate Fetel infetada. RT-PCR.

Palavras-chave adicionais: Pyrus communis, P. pyrifolia, Malus spp., Flexiviridae, ASPV, dot-ELISA, imunoblot,

\begin{abstract}
Biological and molecular diagnosis and nucleotide sequence analysis of the coat protein gene of an isolate of Apple stem pitting virus

Apple stem pitting virus (ASPV) was detected in samples of European pear (Pyrus communis) cvs. Starkrimson and Abate Fetel, and Asian pear (P. pyrifolia var. culta) cvs. Kousui and Housui. The samples were collected in the beginning of autumn 2003 at the Experimental Station of Embrapa Uva e Vinho, Vacaria, RS. Using several combinations of primers, DNA fragments of 269 and 1554 bp were amplified, the latter containing the complete coat protein gene (1131 nt) of ASPV. Another amplified fragment of 291 bp comprised part of the viral polymerase gene. These fragments are excellent tools for the diagnosis of ASPV in pear. Comparison of the nucleotide sequences with sequences of the GenBank showed 89\% identity with sequences from the German isolate of apple, and 85 to $88 \%$ with Polish isolates, both from pear. The herbaceous indicator Nicotiana occidentalis cv. 37B, mechanically inoculated with leaf extracts from cv. Housui, presented necrotic local lesions, marginal leaf necrosis and severe vein necrosis. ASPV was also detected by dot-ELISA in the cvs. Abate Fetel and Kousui, by imunoblot in the cv. Starkrimson and by indexing on Pyronia veitchii, graft-inoculated with buds of the infected cv. Abate Fetel. RT-PCR.

Additional keywords: Pyrus communis, P. pyrifolia, Malus spp., Flexiviridae, ASPV, dot-ELISA, immunoblot,
\end{abstract}

\section{INTRODUÇÃO}

Apple stem pitting virus (ASPV), família Flexiviridae, gênero Foveavirus, ocorre na maioria das cultivares comerciais de macieiras (Malus domestica L.),

\footnotetext{
*Parte da Dissertação de Mestrado do primeiro autor. Universidade de Passo Fundo (2005).
}

pereiras (Pyrus communis L.) e marmeleiros (Cydonia oblonga Mill.) em todas as regiões pomicultoras do mundo, geralmente em combinação com outros vírus. Possui partículas alongadas, filamentosas e flexuosas, de 12 a 15 $\mathrm{nm}$ de espessura e $800 \mathrm{~nm}$ de comprimento (Koganezawa \& Yanase, 1990; 1992). O genoma é composto de RNA de fita simples, senso positivo, com $9306 \mathrm{nt}$ e cinco fases abertas de leitura (ORF - open reading frames) (Jelkmann, 1994). 
As ORFs 1, 2-4 e 5 codificam, respectivamente, a polimerase de RNA, as proteínas do bloco triplo de genes encontrado tipicamente em vírus dos gêneros Potexvirus e Carlavirus, envolvidas no movimento célula-a-célula das partículas virais, e a proteína capsidial (Jelkmann, 1994).

Por ser um vírus latente em macieiras, pereiras e marmeleiros, comum em cultivares comerciais, e por não produzir sintomas visualmente perceptíveis, pode passar despercebido e ser propagado indefinidamente, ocorrendo um alto grau de infecção nos materiais utilizados. Os danos consistem em redução de vigor das plantas, da qualidade dos frutos e da produtividade.

Diversos sintomas estão associados ao ASPV. Entre eles destacam-se as caneluras produzidas em cultivares suscetíveis de macieiras, como a cv. Virginia Crab; o amarelamento das nervuras, o empedramento dos frutos, e o mosqueado vermelho da pêra; a deformação dos frutos e as manchas anelares ferruginosas do marmelo; a epinastia e o declínio do Spy 227; e o descascamento e o nanismo de platycarpa, (Refatti \& Osler, 1975; Stouffer, 1989; Cameron, 1989; Jelkmann, 1997; Paunovic \& Rancovic, 1998; Schwarz \& Jelkmann, 1998; Paunovic et al., 1999).

Entre as indicadoras biológicas do ASPV, destacamse cultivares de macieira e outras espécies do gênero Malus, P. communis e o híbrido Pyronia veitchii (Trabut) Guill.

A enxertia é o único meio pelo qual o ASPV é transmitido para plantas hospedeiras lenhosas. Transmissão experimental por inoculação mecânica foi obtida para Nicotiana occidentalis Wheeler cv. 37B (Van der Meer,1986) e $N$. occidentalis Wheeler subsp. obliqua (Koganezawa \& Yanase, 1990). Leone et al. (1995) demonstraram a retrotransmissão do vírus de $N$. occidentalis para macieiras e pereiras.

Este trabalho foi conduzido com o objetivo de estabelecer o diagnóstico biológico, em plantas indicadoras, e molecular de isolados do ASPV em pereiras por meio de RT-PCR e efetuar a caracterização biológica e molecular parcial de um isolado do vírus.

\section{MATERIAL E MÉTODOS}

\section{Origem do material vegetal}

Folhas e ramos das pereiras européias (P. communis) cvs. Starkrimson e Abate Fetel, e asiáticas (P. pyrifolia var. culta Burm.) cvs. Kousui e Housui foram coletadas na Estação Experimental da Embrapa Uva e Vinho, Vacaria, RS, no outono de 2003. A cultivar Pyrodwarf, um híbrido de P. communis ('Old Home' x 'Bonne Luise D’Avranches') oriunda de cultura de meristemas (cedida gentilmente por Antonio Oliveira Lessa, Epagri, Lages, SC), já avaliada anteriormente neste laboratório, foi utilizada em todo o experimento como controle negativo, livre de ASPV.

\section{Extração de ácidos nucléicos totais, síntese de cDNA e amplificação por PCR.}

A extração de RNA total de folhas e cascas de ramos foi realizada por adsorção de ácidos nucléicos totais em partículas de dióxido de silício (Boom et al., 1990).

A reação de síntese de cDNA constituiu-se, para todas as amostras, de: $1 \mu \mathrm{l}$ de RNA total, 9,6 $\mu \mathrm{l}$ de água, 28 unidades de inibidor de RNAse ( $40 \mathrm{U} / \mu \mathrm{l})$ e $10 \mu \mathrm{M}$ de iniciador oligo dT. A mistura foi incubada por $10 \mathrm{~min}$ a $70^{\circ} \mathrm{C}$ e 5 min no gelo. Posteriormente foram acrescentados $4 \mu \mathrm{l}$ de tampão $5 \mathrm{x}$ da transcriptase reversa M-MLV (Invitrogen), $10 \mathrm{mM}$ de DTT, 2,5 mM de cada dNTP e 200 unidades de transcriptase reversa M-MLV (Invitrogen). A mistura foi incubada a 37 ${ }^{\circ} \mathrm{C}$ por 1 h e a $70{ }^{\circ} \mathrm{C}$ por $15 \mathrm{~min}$.

Para a PCR foram preparados para cada amostra 50 $\mu \mathrm{l}$ da seguinte mistura de amplificação: $5 \mu \mathrm{l}$ de tampão da enzima, 1,5 mM de $\mathrm{MgCl}_{2}$, 2,5 mM de cada dNTP, cinco unidades da polimerase de DNA de Thermus aquaticus (Ludwig Biotecnologia), $1 \mu \mathrm{l}(10 \mu \mathrm{M})$ de iniciadores $(0,2$ $\mu \mathrm{M}$ de cada oligonucleotídio) e $5 \mu \mathrm{l}$ de cDNA. O volume foi completado para $50 \mu \mathrm{l}$ com água esterilizada e deionisada. A mistura foi desnaturada a $95^{\circ} \mathrm{C}$ por $10 \mathrm{~min}$, seguidos de 35 ciclos de amplificação (1 min, desnaturação a $94{ }^{\circ} \mathrm{C}$; $1 \mathrm{~min}$, pareamento a $50^{\circ} \mathrm{C}, 1 \mathrm{~min}$, extensão a $72{ }^{\circ} \mathrm{C}$ ), e uma extensão final de 10 min a $72{ }^{\circ} \mathrm{C}$. Foram utilizados os oligonucleotídeos ASPV1, ASPV2 (Malinowski et al.,1998), ASPV3, ASPV4 e ASPV5 (Jelkmann, 1994) (Tabela 1).

A análise dos produtos da PCR foi realizada em gel de agarose $1,2 \%$, preparado em tampão TBE pH 8,0. A banda correspondente a um dos fragmentos amplificados, de tamanho esperado de $1554 \mathrm{pb}$, obtida com os oligonucleotídeos ASPV3 e ASPV5, foi recortada do gel e o DNA foi eluído com o kit de purificação GFX (Amersham Biosciences) de acordo com as especificações do fabricante.

\section{Ligação do fragmento de 1554 pb ao vetor e transformação de Escherichia coli}

Para a ligação do fragmento ao vetor de clonagem foram adicionados $5 \mu \mathrm{l}$ do DNA purificado, $10 \mu \mathrm{l}$ de tampão ligase $2 \mathrm{X}, 0,06 \mu \mathrm{g}$ do vetor pGEM-T Easy $(0,06 \mu \mathrm{g} / \mu \mathrm{l})$ (Promega), cinco unidades de ligase de DNA de T4 (5 U/ $\mu$ l) (Promega) e $3 \mu \mathrm{l}$ de água esterilizada deionizada. A reação foi incubada por $3 \mathrm{~h}$ a $15^{\circ} \mathrm{C}$. Foram transferidos $200 \mu \mathrm{l}$ de células competentes de $E$. coli DH5 $\alpha$ para tubo Eppendorf e adicionados $20 \mu \mathrm{l}$ da reação de ligação. As células foram incubadas em gelo por 30 min e posteriormente a $42{ }^{\circ} \mathrm{C}$ por $90 \mathrm{~s}$. A mistura foi imediatamente recolocada em gelo e foram adicionados $800 \mu \mathrm{l}$ de meio de cultura LB. Após incubação por $1 \mathrm{~h}$ a $37^{\circ} \mathrm{C}$ e centrifugação por $15 \mathrm{~s}$, retiraram-se $800 \mu \mathrm{l}$ do meio líquido, as células foram ressuspendidas no volume restante de $200 \mu \mathrm{l}$ e plaqueadas em meio de cultura LB sólido com ampicilina (100 $\mu \mathrm{g} / \mathrm{ml}), 40 \mu \mathrm{l}$ de X-Gal (20 $\mathrm{mg} / \mathrm{ml}$ ) e $4 \mu \mathrm{l}$ de IPTG (200 mg/ml) por placa. As colônias brancas, recombinantes, foram transferidas para tubos de ensaio com meio de cultura LB com ampicilina e incubadas com agitação de 120 rpm durante a noite a $37^{\circ} \mathrm{C}$.

\section{Extração e digestão de DNA plasmidial}

O DNA plasmidial de clones transformados foi 
extraído utilizando-se o kit FlexiPrep (Amersham Biosciences) de acordo com as instruções do fabricante. A confirmação da presença de fragmento de ASPV nos plasmídeos recombinantes foi realizada por clivagem com a enzima de restrição Eco RI e visualização do fragmento em gel de agarose como mencionado anteriormente.

O clone recombinante foi seqüenciado e a seqüência de nucleotídeos e de aminoácidos deduzidos foi analisada e comparada com as seqüências do banco de dados GenBank, utilizando-se a função BLAST do NCBI (National Center for Biotechnology Information - www.ncbi.nlm.nih.gov).

\section{Indexação Biológica}

As cultivares Abate Fetel e Housui foram indexadas por borbulhas em duas indicadoras, a pêra européia cv. Beurrée Hardy e o híbrido $P$. veitchii, ambas enxertadas no porta-enxerto $P$. calleryana (Decaisne) com três repetições por tratamento. As plantas inoculadas foram mantidas em casa de vegetação.

Folhas das pereiras européias cvs. Starkrimson e Abate Fetel, e asiáticas cvs. Kousui e Housui, suspeitas de estarem infetadas com o ASPV, foram maceradas em tampão fosfato de potássio 0,01 M e nicotina 2,5\%, pH 7,5. Para a tentativa de transmissão experimental do ASPV, o extrato foi inoculado mecanicamente em folhas primárias de $N$. occidentalis, $N$. occidentalis var. obliqua e $N$. occidentalis 37B, com três repetições por tratamento. A RT-PCR foi executada conforme descrito acima com os oligonucleotídeos ASPV1 e ASPV2.

\section{Dot-ELISA e imunoblot}

Para o dot-ELISA utilizaram-se como antígeno extratos de cascas de ramos e de folhas de pereiras cvs. Abate Fetel e Kousui, e P. veitchii usada na indexagem de ASPV, enxertada com gemas da cv. Abate Fetel.

As amostras foram maceradas em tampão TBS, $\mathrm{pH}$ 7,5 com sulfito de sódio a $0,2 \%(\mathrm{p} / \mathrm{v})$, na proporção $1: 5$, e aplicados $20 \mu \mathrm{l}$ sobre membrana de nitrocelulose. A seguir a membrana foi mergulhada em solução bloqueadora [TBS, pH 7,5, Triton X-100 a 2\% (v/v), leite em pó desnatado (LPD) a $2 \%(\mathrm{p} / \mathrm{v})]$ por $1 \mathrm{~h}$ sob agitação lenta. A membrana foi tratada com $10 \mu$ l de anti-soro contra ASPV (gentilmente doado por L. A. Suita de Castro, Embrapa Clima Temperado,
Pelotas, RS) diluído em TBS com LPD a 2\% (p/v) por $16 \mathrm{~h}$ sob agitação, lavada em TBS com Tween 20 a 0,05\% (v/v) sob agitação forte e incubada por $1 \mathrm{~h}$ com adição de $10 \mu \mathrm{l}$ do conjugado universal anti-IgG (Sigma), diluído em TBS com LPD a $2 \%(\mathrm{p} / \mathrm{v})$. Em seguida, procedeu-se a nova lavagem da membrana e a revelação foi realizada com a adição dos substratos NBT e BCIP (Sigma) (Fajardo et al., 2000). Para o imunoblot as membranas receberam idêntico tratamento, exceto que as proteínas totais separadas em géis descontínuos de poliacrilamida com SDS (3,8\%/12\%, 90 $\mathrm{min} / 120 \mathrm{~V})$ foram transferidas por eletroforese $(1 \mathrm{~h} / 80 \mathrm{~V})$ para membranas de nitrocelulose. Utilizou-se o anti-soro ASPV 647 contra a CP do isolado PA66 (cedido gentilmente por W. Jelkmann, Agência Federal Biológica, Alemanha).

\section{RESULTADOS E DISCUSSÃO}

Com os oligonucleotídeos ASPV4 e ASPV5 foi amplificado um fragmento de 269 pb (Figura 1A) de extratos foliares das quatro cultivares de pereira testadas. Esses oligonucleotídeos representam, portanto um excelente instrumento para detecção do ASPV. A partir deste resultado, as amostras que permitiram a amplificação deste fragmento com este par de oligonucleotídeos passaram a ser utilizadas como controle positivo da infecção por ASPV. A combinação dos oligonucleotídeos ASPV3 e ASPV5 resultou na amplificação de um fragmento de 1554 pb (Figura 1B), contendo o gene completo da proteína capsidial (CP), o qual foi clonado, seqüenciado e a sequência obtida depositada no banco de dados Genbank sob número de acesso AY572458.

Dos extratos foliares de $N$. occidentalis 37B inoculada mecanicamente com extrato foliar de pereiras infetadas amplificou-se um fragmento de 291 pb (Figura 1C) utilizando-se os oligonucleotídeos ASPV1 e ASPV2, que contém parte do gene da polimerase viral.

A maior identidade de nucleotídeos do isolado de ASPV (89\%) foi observada com um isolado alemão (D21829) e a menor (85\%) com isolados poloneses (AF345893 e AF345894). A maior identidade de aminoácidos deduzidos foi de 84\% com dois isolados poloneses de pereira (AAK30563 e AAK30566) e a menor identidade foi de 75\% com dois isolados alemães (BAA04852 e BAA04853). Foi possível,

TABELA 1 - Oligonucleotídeos usados para detecção do isolado BR1 do Apple stem pitting virus, posição no genoma e tamanho esperado dos fragmentos

\begin{tabular}{llclc}
\hline \hline Nome (Sigla) & Seqüência 5' - 3' & Posição no genoma & Orientação & Tamanho esperado \\
\hline ASPV1 & AGCGGTTGCCTATTTTTGCTCC & $3480-3501$ & Complementar & $291 \mathrm{pb}^{1}$ \\
ASPV2 & GTCAGGTCAAAGATGCTGAAA & $3750-3770$ & Reverso & \\
ASPV3 & GTACATGAGTAACTCGAGCC & $7709-7728$ & Complementar & $1554 \mathrm{pb}^{2}$ \\
ASPV4 & CTCTTGAACCAGCTGATGGC & $8993-9012$ & Complementar & $269 \mathrm{pb}^{3}$ \\
ASPV5 & ATAGCCGCCCCGGTTAGGTT & $9243-9262$ & Reverso & \\
${ }^{1}$ combinação: & ASPV1 e ASPV2. ${ }^{2}$ Combinação: ASPV3 e ASPV5. ${ }^{3}$ Combinação: ASPV4 e ASPV5.
\end{tabular}



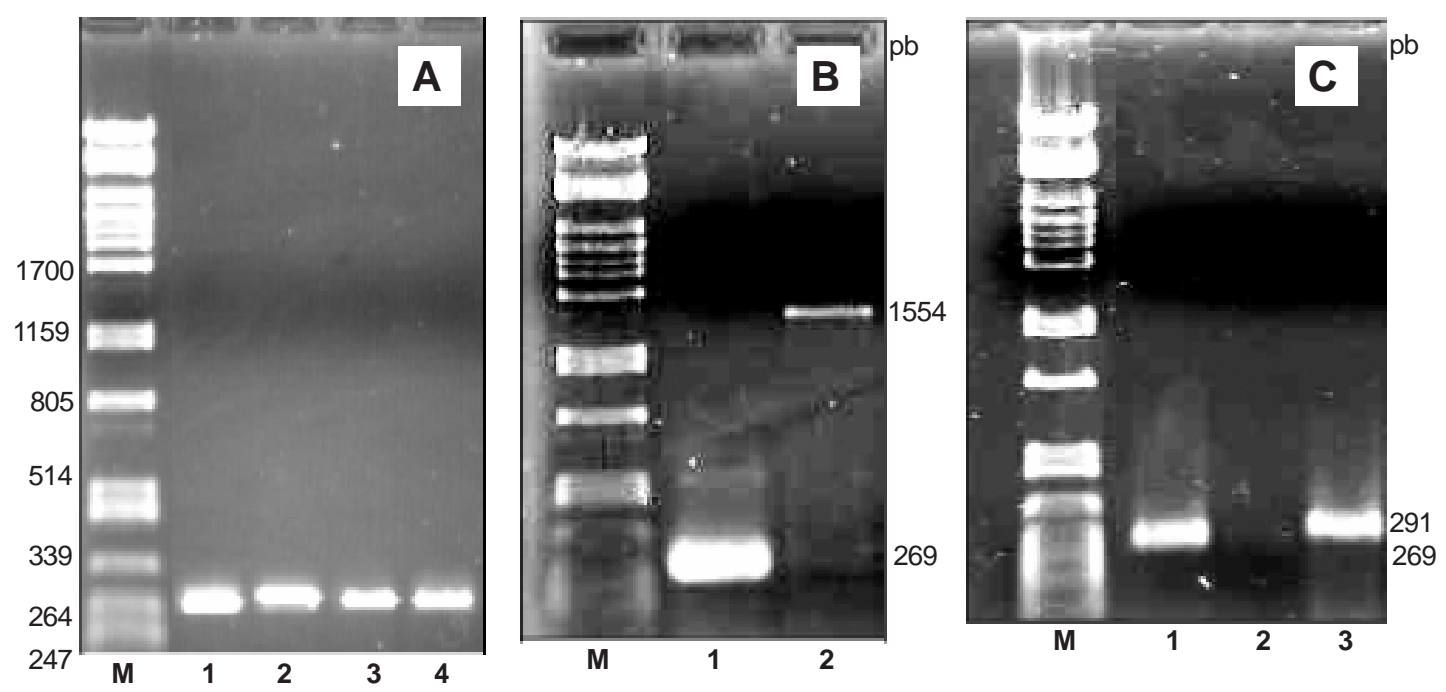

FIG. 1 - Análise de produtos da RT-PCR por eletroforese em gel de agarose 1,2\%. (M) DNA $\lambda /$ PstI. A) Iniciadores Apple stem pitting virus (ASPV) 4 e 5: 1- cv. Starkrimson; 2- cv. Abate Fetel; 3- cv. Kousui; 4- cv. Housui; B) Iniciadores ASPV 3 e 5: 1- Controle infetado, cv. Housui; 2- cv. Abate Fetel. C) Iniciadores ASPV 1 e 2: 1- Controle infetado, cv. Housui; 2- controle sadio, cv. Pyrodwarf; 3- Nicotiana occidentalis 37B.

na análise das seqüências de nucleotídeos e aminoácidos deduzidos, associar esse clone a outros isolados do mesmo vírus (Tabela 2), confirmando a identificação do isolado como ASPV. Como regra geral, espécies na família Flexiviridae têm entre seus genes completos de CP e polimerase, identidade de $\geq 72 \%$ de nucleotídeos e $\geq 80 \%$ de aminoácidos. Espécies de gêneros diferentes têm menos de $40 \%$ de identidade de nucleotídeos e de aminoácidos (Adams et al.,2004).

O alinhamento da seqüência obtida do isolado brasileiro com as seqüências dos isolados alemães e poloneses revelou uma diferença no tamanho do gene de CP quando comparado com os isolados alemães, não diferindo substancialmente dos isolados poloneses. Os dois isolados alemães (CP de $1244 \mathrm{nt}$ ) apresentam duas regiões diferentes no gene $\mathrm{CP}$, uma com deleção e outra com inserção de aproximadamente 100 nucleotídeos. Mesmo assim, o isolado brasileiro apresentou alta identidade (89\%) com o isolado alemão. Malinowski (1998) também verificou essa diferença dos isolados poloneses (CP de 1124 a $1128 \mathrm{nt}$ ) em relação aos isolados alemães. Não estão elucidadas nem a causa nem o efeito dessas mutações, merecendo o assunto, portanto, estudos adicionais.

Embora pela análise das seqüências os valores de identidade sejam suficientemente altos para permitir que se determine com segurança a identidade do vírus encontrado nas amostras analisadas, a variação apresentada pode ser explicada pela variabilidade natural existente entre isolados de uma mesma espécie ou isolado viral, especialmente significativa nesta espécie. Nas condições brasileiras ainda é desconhecida a variabilidade do ASPV. Por diferir das condições climáticas de outras regiões do mundo, a pressão de seleção no Brasil poderia produzir variantes distintas daquelas encontradas em outras regiões.

Nas tentativas de transmissão mecânica, de 36 plantas inoculadas com extrato foliar da cv. Housui, somente uma planta foi infetada. A infecção pelo ASPV caracterizou-se por forte amarelamento, seguido de necrose de nervuras de toda a folha e lesões locais necróticas, além de necrose das extremidades apicais e laterais da lâmina foliar de $N$. occidentalis 37B. A necrose sistêmica de nervuras não foi relatada para os isolados do hemisfério norte, facilmente transmissíveis pela via mecânica (Van der Meer , 1986; Van Dijk et al., 1987; Koganeza \& Yanase, 1990; Leone et al., 1995; Jelkmann, 1997). O isolado ASPV BR1, aqui descrito, apresenta, portanto, comportamento biológico diferente. Sua transmissão mecânica foi difícil, o que confirma diferenças biológicas entre isolados de diferentes regiões geográficas já relatadas (Pilotti et al., 1995). Assim, pode-se considerar adequado o uso de $N$. occidentalis 37B para o diagnóstico de isolados de ASPV do sul do Brasil, como complemento à indexagem do vírus em indicadoras lenhosas.

Das duas espécies lenhosas indexadas, somente $P$. veitchii desenvolveu sintomas da infecção pelo ASPV, constituídos de manchas cloróticas nos espaços entre as nervuras secundárias, lesões locais necróticas, anéis e meiosanéis cloróticos e bandeamento clorótico de pouca extensão de nervuras secundárias.

O dot-ELISA revelou-se um teste sensível e confiável para a detecção do ASPV em todas as cultivares e tecidos analisados, cujos resultados foram confirmados pela PCR. As manchas roxas-rosadas das amostras infetadas contrastam fortemente com o amarelo-esverdeado do controle sadio (não mostrado). O imunoblot detectou uma forte reação positiva e específica dos anticorpos produzidos contra um isolado alemão do ASPV com uma proteína de 
TABELA 2 - Comparação de identidade (\%) das seqüências de nucleotídeos (diagonal superior) e de aminoácidos deduzidos (diagonal inferior) do gene da proteína capsidial do Apple stem pitting virus BR1 com as respectivas seqüências de isolados disponíveis em bancos de dados

\begin{tabular}{|c|c|c|c|c|c|c|}
\hline \multirow[b]{2}{*}{ Isolado Viral } & \multirow{2}{*}{$\begin{array}{l}\text { Brasil } \\
\text { Br1 (1) }\end{array}$} & \multicolumn{2}{|c|}{ Alemanha } & \multicolumn{3}{|c|}{ Polônia } \\
\hline & & Pa66 (2) & PSA H (3) & GNKVII 34 (4) & St132 (5) & St113 (6) \\
\hline BR1 & & $89 \%$ & $88 \%$ & $85 \%$ & $85 \%$ & $88 \%$ \\
\hline PA66 & $75 \%$ & & $99 \%$ & $80 \%$ & $88 \%$ & $91 \%$ \\
\hline PSA-H & $75 \%$ & $89 \%$ & & $80 \%$ & $88 \%$ & $90 \%$ \\
\hline GNKVII/34 & $84 \%$ & $76 \%$ & $83 \%$ & & $81 \%$ & $82 \%$ \\
\hline ST132 & $82 \%$ & $76 \%$ & $76 \%$ & $74 \%$ & & $92 \%$ \\
\hline ST113 & $84 \%$ & $76 \%$ & $78 \%$ & $74 \%$ & $89 \%$ & \\
\hline
\end{tabular}

Números de acesso no GenBank : (1) AY572458/AAS78637; (2) D21829/BAA04853; (3) D21828/BAA04852, (4) AF345893/ AAK30563; (5) AF345894/AAK30565; (6) AF345895/AAK30566; (1), (3), (4), (5) e (6) de pêra; (2) de maçã.

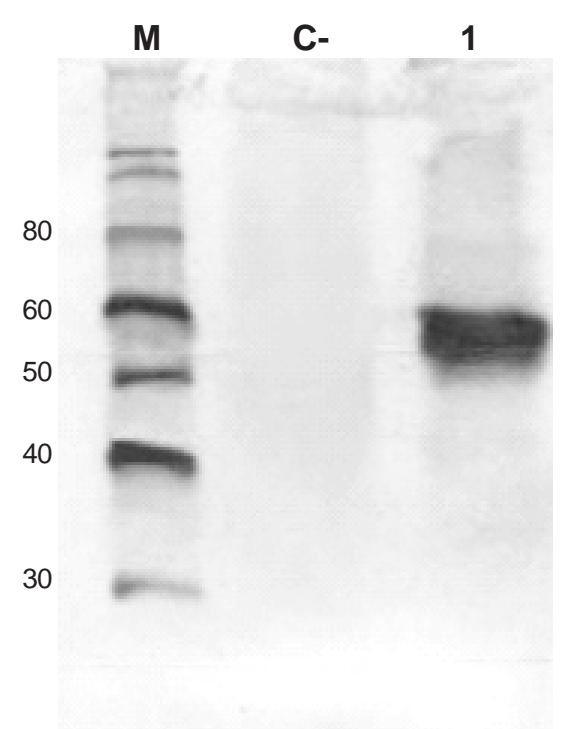

FIG. 2 - Análise por western blot. M- Marcador molecular, em kDa (Invitrogen). C- Pyrus communis (controle negativo) cv. Pyrodwarf sadia (folha), 1- cv. Starkrimson (casca de ramos).

cerca de 55 kDa (Figura 2). Jelkmann (1994) e Koganezawa \& Yanase (1990) observaram uma proteína de 48 kDa correspondendo à proteína capsidial em folhas de $N$. occidentalis inoculada com ASPV. Apesar da diferença entre o tamanho previsto segundo cálculo computacional de 44 $\mathrm{kDa}$. deduzido da seqüência de aminoácidos da subunidade protéica do ASPV e os valores observados em western blot, os autores consideram-nos compatíveis. Similarmente ao que se constata no presente estudo, a diferença entre o valor calculado e o observado foi atribuída à alta hidrofilicidade da proteína capsidial de ASPV, a exemplo de discrepância similar já observada com a proteína capsidial de Shallot virus $X$ (ShVX), família Flexiviridae gênero Allexivirus, sugerida por Kanyuka et al. (1992), que determina um aumento aparente do tamanho da molécula em conseqüência de uma redução da mobilidade eletroforética. As mutações do ASPV mencionadas acima não afetaram, aparentemente, determinantes antigênicos, uma vez que o ASPV BR1 reagiu positivamente com ambos os anti-soros produzidos contra isolados europeus em dot-ELISA e imunoblot.

A implementação de testes diagnósticos biológicos, sorológicos e moleculares demonstrada neste trabalho apresenta relevância para a detecção do ASPV em Malus sp., Pyrus sp., Pyronia sp., Cydonia sp. e hospedeiros experimentais, permitindo a indexagem segura de plantas, de maneira a evitar a disseminação do ASPV em materiais propagativos.

\section{AGRADECIMENTOS}

Os autores agradecem a Marcos F. Vanni pelo excelente suporte técnico, ao pesquisador João Bernardi pela coleta e envio das amostras analisadas, à FINEP e à Embrapa Uva e Vinho, pela bolsa concedida à primeira autora.

\section{REFERÊNCIAS BIBLIOGRÁFICAS}

ADAMS, M.J., ANTONIW, J.F., BAR-JOSEPH, M., BRUNT. A.A., CANDRESSE, T., FOSTER, G.D., MARTELLI, G.P., MILNE, R.G. \& FAUQUET, C.M. The new plant virus family Flexiviridae and assessment of molecular criteria for species demarcation. Archives of Virology 149:1045-1060. 2004.

BOOM, R., SOL, C.J.A., SALIMANS, M.M.M., JANSEN, C.L., WERTHEIM VAN DILLEN, P.M.E. \& VAN DER NOORDAA, J. Rapid and simple method for purification of nucleic acids. Journal of Clinical Microbiology 28:495-503. 1990.

CAMERON, H.R. Pear vein yellows. In: Fridlund, P.R. (Ed.) Virus and viruslike diseases of pome fruits and simulating noninfectious disorders. Cooperative Extension College of Agriculture and Home Economics. Washington State University. 1989. pp. 175-179.

FAJARDO, T.V.M., KUHN, G.B., EIRAS, M. \& NICKEL, O. Caracterização parcial de um isolado de Grapevine fanleaf virus. Fitopatologia Brasileira 25:505-511. 2000.

JELKMANN, W. Nucleotide sequences of Apple stem pitting virus and of the coat protein gene of a similar virus from pear associated with vein yellows disease and their relationship with 
potex- and carlaviruses. Journal of General Virology 75:15351542. 1994.

JELKMANN, W. Apple stem pitting virus. In: D. Vesely \& P. Monette (Eds.) Recent Research Development in Plant Pathology - filamentous viruses of woody plants. Trivandrum 695.008, India, 1997. capítulo 12, pp.133-142.

KANYUKA, K.V., VISHNICHENKO V.K., LEVAY K.E., KONDRIKOV, D.Y.U., RYABOV, E.V. \& ZAVRIEV, S.K. Nucleotide sequence of shallot virus X RNA reveals a 5'-proximal cistron closely related to those of potexviruses and a unique arrangement of the 3'-proximal cistrons. Journal of General Virology 73:2553-2560. 1992.

KOGANEZAWA, H. \& YANASE, H. A new type of elongated virus isolated from apple trees containing the stem pitting agent. Plant Disease 74:610-614. 1990.

KOGANEZAWA, H. 1992. Apple stem pitting virus. Plant viruses online: Descriptions and list from the VIDE Database. Disponível em: http://image.fs.uidaho.edu/vide.descr027.htm. Acesso em: 02/10/2003.

LEONE, G., LINDNER, J.L., JONGEDIJK, G. \& VAN DER MEER, F.A. Back transmission of a virus associated with apple stem pitting and pear vein yellows, from Nicotiana occidentalis to apple and pear indicators. Acta Horticulture 386:72-77. 1995.

MALINOWSKI, T., KOMOROWSKA, B., GOLIS, T. \& ZAWADZKA, B. Detection of apple stem pitting virus and pear vein yellows virus using reverse transcription - polymerase chain reaction. Acta Horticulture 472:87-95. 1998.

PAUNOVIC, S. \& RANKOVIC, M. Relationship between quince fruit deformation virus and some pome fruit viruses. Acta Horticulture 472:125-133. 1998.

PAUNOVIC, S., MAKSIMOVIC, V., RANKOVIC \& S. RADOVIC. Characterization of a virus associated with pear stony pit in cv. Württemberg. Journal of Phytopathology 147:695-700. 1999.

PILOTTI, M., FAGGIOLI, F. \& BARBA, M. Characterization of Italian isolates of pear vein yellows virus. Acta Horticulturae 386:142-154. 1995.

REFFATI, E. \& OSLER, R. Possible relationships among pome fruit viruses detected in graft transmission trials. Acta Horticulture 44:201-208. 1975.

SCHWARZ, K. \& JELKMANN, W. Detection and characterization of European apple stem pitting virus sources from apple and pear by PCR and parcial sequence analysis. Acta Horticulturae 472:75-83. 1998.

STOUFFER, R.F. Apple stem pitting. In: Friedlund, P.R. (Ed.) Virus and viruslike diseases of pome fruits and simulating noninfectious disorders. Cooperative Extension College of Agriculture and Home Economics. Washington State University. 1989. pp.138-144.

VAN der MEER, F.A. Observations on the etiology of some virus diseases of apple and pear. Acta Horticulture 193:73-74. 1986.

VAN DIJK, P., VAN DER MEER, F.A. \& PIRON, P.G.M. Accessions of Australian Nicotiana species suitable as indicator hosts in the diagnosis of plant virus diseases. Netherlands Journal Plant Pathology 93:73-85. 1987. 